\title{
Pregnancy Related Breast Soreness
}

National Cancer Institute

\section{Source}

National Cancer Institute. Pregnancy Related Breast Soreness. NCI Thesaurus. Code C92855.

The tenderness of the breasts during pregnancy due to changes in the hormonal levels and increased breast tissue growth. 